\title{
Evidence-Based Guidelines for Recording Slide-Based Lectures
}

\author{
Dina Kurzweil $^{1}$ (D) $\cdot$ Karen Marcellas $^{2} \cdot$ Brandon Henry $^{2} \cdot$ Eric Meyer $^{3}$ (D) \\ Published online: 31 July 2020 \\ (C) This is a U.S. government work and not under copyright protection in the U.S.; foreign copyright protection may apply 2020
}

\begin{abstract}
Pre-recorded lectures can be an efficient way to convey instructional content to students in distributed environments, but videos that are not of high quality can potentially reduce student engagement. These guidelines are designed to help faculty and staff prepare and develop effective recorded lectures using presentation software such as PowerPoint and Google Slides. The guidelines are evidence-based and represent best practices for the use of media in education. Effective creation of pre-recorded lectures with presentation software is not an easy process, but the time and effort invested will generate a valuable resource.
\end{abstract}

Keywords Pre-recorded lecture $\cdot$ Video $\cdot$ Lecture $\cdot$ Slides $\cdot$ Media $\cdot$ Lecture

\section{Introduction}

In the face of the challenges confronting faculty who want to extend their teaching into distributed environments, incorporating digital technologies by methods such as pre-recording lectures provides alternative instructional methods that can enable the thoughtful creation of more engaging content.

Video lectures are becoming more common in medical education [8] and are found in many distributed learning environments, for which enrollments are growing faster than in any other educational sector [1]. While the use of video lectures was already increasing, the COVID-19 pandemic that shut down classrooms throughout the world has resulted in even more faculty members turning to this method [18]. Although recording a lecture is not a new idea, many schools focus on recording face-toface lectures so that students can review them later. Such live recorded lectures can suffer from poor audio or video quality, and from the fact that these lectures are designed for ephemeral classroom delivery to an audience that is present rather than more

Dina Kurzweil

dina.kurzweil@usuhs.edu

1 Graduate Programs in Health Professions Education \& Education \& Technology Innovation Support Office, Uniformed Services University of the Health Sciences, Bethesda, MD, USA

2 Education \& Technology Innovation Support Office, Uniformed Services University of the Health Sciences, Bethesda, MD, USA

3 Department of Psychiatry, Uniformed Services University of the Health Sciences, Bethesda, MD, USA enduring use in an online environment with a more distant audience. As well, given the limitations on face-to-face class gatherings due to the COVID-19 pandemic, it might not be possible for faculty members to offer live lectures to students in the near future. Crafting a pre-recorded lecture for repeated use requires planning and preparation. Such care saves time in the long run because it enables the video to be reused over a number of terms.

Many different tools allow faculty and staff to create a video recording of a lecture that will engage students and contribute significantly to their learning. Creating effective video recordings requires mastery of two skill sets: the development of effective educational slide-based lectures and the effective recording and distribution of video content. While some faculty and staff members may have knowledge of or training in one of these skill sets, many do not. Even those who do have training may not have learned how to integrate the two skill sets to provide an engaging and educationally grounded experience for students via a pre-recorded slidebased video lecture. The following guidelines are evidencebased and are organized into three distinct phases of video creation: planning the content, creating the slides, and recording the lecture. These guidelines provide faculty and staff with guidelines drawn from best practices in both skills that they can use to increase the power of their educational videos.

\section{Background}

Research shows that some of the primary barriers to developing online courses are constraints on faculty time and limits to 
technical knowledge $[1,22]$. Thus, finding ways to help support the development of videos using presentation slides is a step towards making more online products available. However, quantity should not be the primary goal; quality should be. Such videos are most effective when they are interesting and engaging to students [5], so preparing faculty to create such videos should include letting them know how to make videos more engaging, not just how to create them. Making engaging videos will, however, take more time than simply recording a classroom lecture when it is delivered. For that reason, it is important that academic institutions are prepared for the upfront investment of time and energy necessary to create effective slide-based video lectures with presentation software [21].

The guidance offered here is intended to help institutions as they navigate this process. While the authors have reviewed the literature and found no guidance specific to pre-recording slide-based lectures, they have found literature on effective face-to-face lecturing [24], lecture slide development [25], and efficient production techniques and video integration as well as research on teaching, learning, and multimedia design $[5,6,12]$. In developing the guidelines, the authors drew upon these sources as well as extensive experience in instructional design, instructional technology, and video production in order to identify practices that are both technologically and instructionally sound.

\section{Planning}

1. Start with a good foundation — ensure you are using sound instructional practices

If the lecture you are pre-recording does not have objectives, or the teaching modality is not matched appropriately to the goals (e.g., a lecture, live or recorded, is unlikely to successfully teach application of concepts), any recorded lecture will have pedagogical difficulties [2]. Ensure that a video lecture is the best instructional strategy for your objectives [8]. A video lecture may not be the best way to teach skills or attitudes. Video lectures are an appropriate strategy for conveying facts and foundational knowledge but may not be an appropriate strategy for teaching students how to evaluate or create content. Consider other modalities for such objectives (e.g., videos of skill performance, white-board style videos, interactive online content, online discussion groups).

(a) Before recording ensure your objectives are achievable, focused, and, if applicable, mapped to the course blueprint.

(b) Be sure to incorporate your learning objectives into your video. In addition to explicitly stating your objectives within the first minute of the video, it is important to ensure you have mechanisms for assessing your objectives (see guideline 1.d).

(c) Faculty should consider tracking click rates and/or website metadata, which can provide a means for monitoring student use of the video lecture.

(d) Without the natural checks for understanding that occur in a live lecture, faculty should consider providing pauses during their video lecture for students to answer a question or, if available, provide built-in quizzes. If case examples or vignettes are used as part of built-in quizzes, application of content can also be assessed. Alignment of objectives and assessments is critical to ensure successful learning takes place [2]. Tracking student quiz completion and performance is another important means for confirming that videos are appropriately aligned with learning objectives and that students are engaging with the material (see guideline 1.c).

(e) The natural student interaction found in a classroom/ lecture hall can also be a critical part of the learning process. As such faculty should consider integrating discussion boards/forums or other tools for two-way communication with their video(s).

(f) The timing of live lectures often provides a scaffold and sets a pace for students. Providing all of the lectures at one time can be overwhelming. Faculty should carefully consider when content will be released (e.g., all at once, weekly, daily, or only upon completion of other content) and incorporate this information into the course syllabus to ensure appropriate curricular pacing.

(g) Faculty should carefully consider how recorded videos will be integrated with the rest of the curriculum. Specifically, will the video links be located in a sequential format, with similar content (e.g., small groups, lab assignments), and/or near associated content (e.g., note sets, additional reading).

\section{Keep video lectures short, about 15 min maximum}

Many recent studies support the recommendation to make video lectures short, preferably 6-12 $\mathrm{min}$, with $15 \mathrm{~min}$ as an absolute maximum $[4,5,12]$. While live lectures are often forced into consistent blocks of time (e.g., $60 \mathrm{~min}, 90 \mathrm{~min}$ ) recorded video lectures can be any length. Given that shorter videos are more likely to be watched all the way through and have higher retention, it is a good idea to split previously longer lectures into smaller sections of 6-12 $\mathrm{min}$.

(a) When breaking up longer presentations, organize content into specific and narrow topics. For example, instead of creating a 30-min video lecture on motivation, consider two separate video lecturesone on intrinsic motivation and one on extrinsic motivation. 
(b) Complicated material may require students to watch video lectures in a specified order in order to make connections and understand relationships to see where content fits into a larger blueprint (e.g., they might need to watch anatomy, then physiology, then pathology). Specifically labeling these video lectures as sequential chapters can let students know that the video lectures are related and build upon each other. As mentioned in guideline 1.f, faculty should provide a table of contents or outline of these sections in their syllabus and/or learning management system to help students understand how the curriculum is scaffolded (and which videos to watch first).

\section{Prepare a script}

Write a script or use the "notes section" of the slide to remind you of what you need to say. This will help you organize and edit your thoughts before you begin recording.

(a) To get started with your script, you can practice giving your lecture and use Google voice to text, or the voice to text options on your phone, to record a transcript. While your final recording might not align completely with this script, going through this process can still improve the end product. Practicing before you make your final recording will allow you to determine what you want to say on camera and also help you to feel more comfortable when you are saying it.

(b) Creating a script can also make it easier to anticipate visuals (e.g., animations, graphics, and photos) and plan how to interact with content on the screen. For example adding the word "CLICK" in brackets in your notes reminds you that you need to click the mouse to make something happen on the screen.

(c) Treat your slide notes as the foundation of the material for your students. Once the recording has been produced, the script or notes in slides can be used to create transcripts, closed captioning, and/or note-taking handouts.

(d) When developing your script, remember to build in time to incorporate checks for understanding. Consider posing a question and asking the students to pause the video to think about the answer before moving on, or using multiple choice questions, either built into the video if available or built in an external tool and provided alongside the video.

(e) Practice your presentation often and go through it at least once with an audience who will provide feedback.

4. Review laws and relevant regulations

(a) Remember to check copyright and other intellectual property laws and regulations when you include images or any materials created by others in your slides. If you want to use copyrighted materials seek permission early, as this can be a lengthy process. Also consider seeking copyright-free content, such as that provided by Creative Commons (https://creativecommons.org).

(b) Consider using web search ts filters to ensure your images are all labeled for reuse and are copyright free then double check the actual site they sit within.

(c) Review and follow applicable accessibility laws and regulations.

\section{Creating Content and Slides}

\section{Draw people in from the moment the video starts}

Create an engaging introduction that will draw people in and make them want to continue with the lesson $[9,16,17,20]$. You do not need to mention introductory information if it is already on your title slide (e.g., your name and the course title), enabling you to jump right to your introduction. If you do not grab your audience's attention in the first $30 \mathrm{~s}$, they may not continue watching your presentation and/or engage with your content [14].

(a) Providing an image or video of the faculty member is a great way to personalize a video lecture and make it more engaging. Previous work has shown that the use of a faculty video is rarely distracting (in one study [7], only $10 \%$ of the students found it distracting) and typically increases learner engagement. It does not, however, appear to improve retention $[3,7]$. Thus, faculty should determine which approach they will take based on their available resources and carefully consider other means to increase engagement if a video feed of the faculty is not utilized.

(b) Another method for increasing engagement is the use of narrative. Your lecture should take your audience on a mental journey, integrating with previous experiences and knowledge, and providing examples of real-world application of the topics you will be discussing. One way to do this is to think of it less as lecturing and more as telling a story, which can engage students and make them more likely to remember your content $[10,23]$. Or you can also try to fit the topic itself into a narrative structure with a clear beginning, rising action (middle), and resolution (end), such as framing it as the search for an answer to a question, or an "origin story."

\section{Keep text in slides to a minimum}

Your slides should contain mostly visuals; text on the screen should be limited to a few words per screen at most. More detailed information can be provided in handouts. 
Avoid the mistake of outlining your presentation on the slides - keep your outline in your notes and copy only the key points to the slides. You should not be reading the slides to your students as part of your presentation!

(a) If using text, use bullet points rather than complete sentences or paragraphs. Studies show that students will try to read whatever text appears on the screen - which means they are missing whatever the narrator happens to be saying at the same time [6]. Using bullet points highlights the key concepts and helps the students focus their attention appropriately while your narration provides details.

(b) The on-screen text should highlight important points or contain the "takeaways" or critical notes you would expect students to take, not simply explanations or nice-tohave information. Think of your slides as billboards on a highway; your audience should get the main idea of your slide within $3 \mathrm{~s}$.

(c) When providing data on your slides, avoid doing a "data dump" and clumping all of your statistics on one slide. Tables can display a great deal of information, but unless you need to visually compare the items contained in them, tables do not make compelling slides. Split up your tables and limit your data to one statistic per slide. If you can include an image that relates to your data, that will help your audience interpret the significance and meaning of the statistic [15].

(d) Another way to reduce on-screen text while ensuring students have access to the text later is to provide downloadable handouts. Providing expanded information in written format allows students to use those materials to focus on the topics that are relevant to them and to engage with the material at their own pace. As mentioned above (guideline 3.c) the notes you write for your slide can serve as the foundation for a handout. You might also consider providing a digital copy of the objectives, a detailed outline, a glossary of key terms, practice questions, and/or case examples/vignettes to accompany your video lecture.

(e) One caveat to guideline 6 is that if your audience contains a large number of people who are not native speakers of the language in which you are giving the presentation, you may want to include more words on a slide to aid in their comprehension. Having your handouts - especially note sets - translated can also be helpful.

7. Make sure graphics in slides complement and do not compete with narration

Select graphics for your slides that complement the words you use in the video rather than compete for the students' attention. This follows Clark and Mayer's [6] Coherence Principle, which highlights the need to avoid unnecessary text, sounds, and images in multimedia teaching so that you focus only on the presentation of the necessary information.

Adding interesting but unnecessary material can hurt the learning process since it increases the cognitive load [19].

(a) Use quality graphics that are easily seen by the students and are not disproportionately stretched, pixelated, or blurry.

(b) Graphics should not be word heavy. You do not want to show a busy flow chart with lots of words on the screen. Offer that as a handout (as discussed in guidelines 3.c and 6.d, above) or break up the flow chart into different steps or phases and show them on different screens. For a slide with a large number of labels (such as anatomy or component labels), consider limiting the amount of labels per slide to specific sections, functions, or other blocks of content that can be discussed over multiple slides.

8. Use animations and "build" slides sparingly and appropriately

If you plan to incorporate animations or automated builds into your slides, keep in mind that these are most effective when they are conveying a process; they are not necessarily the best choice for conveying textual information [6]. Slides with many labels are good candidates for an animated text build, especially when planned in conjunction with the narration. This can be especially useful if you introduce each label in a quiz fashion: "Which structure is X? (wait a moment, animate the label) "Here it is." As mentioned previously, the use of animated text builds will be more successful if content on each slide is thoughtfully limited as described in guideline 7. Avoid using complicated animations (e.g., fly in text) or transitions (e.g., rotating windows) unless they themselves add meaning to the content. Otherwise effects like this just add to the cognitive load and distract from your content [16].

\section{Pace graphics with narration}

While you should use graphics that complement rather than compete with on-screen text, as noted above (7.b), you should also be sure that any graphics you use that are supporting the text are timed appropriately. Time any text or images that appear on your slides to display at the same time that you, the narrator, speak the text or discuss the graphic. Think about how news or opinion programs present images to accompany the dialog. This is another way to reduce cognitive load to help students focus on your content [19].

(a) Consider pacing your narration by having specific content show up at specific times (as mentioned in guideline 8), so students cannot read ahead. 
(b) Multimedia learning theory suggests that displaying graphics and talking about them later are not as effective as introducing the images at the very time you begin speaking about them [6].

\section{Maximize the shelf life of your presentation}

While it is important to critically review content regularly to ensure that content is current, avoid including material that will unnecessarily date your content.

(a) For example, eliminate phrases like "last week's assignment" or "this week's football game" and remove references to class dates or the year.

(b) Also consider that students may view lectures out of order, and referring to "the previous lecture" may be confusing. When referencing another lecture, be sure to refer to the specific lecture by topic or name.

(c) Finally, if you wish to refer to websites as part of your presentation, be aware that websites, apps, and other online content may become out of date. Consider what you are showing and why. Also note that most current technology does not allow you to incorporate active hyperlinks in videos without extensive work in post-production. If you want the students to click on links, it is best to provide the links in a document that is separate from the video, with explanations of what they are and when (and why) students should click on them.

\section{Recording the Lecture}

\section{Leverage your verbal communication}

Your voice will be the students' primary connection to the content, so think about how you sound to them.

(a) Your speaking style should be professional, but still relatable and personable. You can begin to incorporate such a style by thinking about how you would describe the content to someone at a social event $[6,11]$. Use conversational language and frequent stories or realworld examples, and incorporate elements of your personality into your lecture.

(b) Do not read content directly from your slides. It is difficult for students to read the same content they are hearing [13]. A script (guideline 3) that is separate from the slides can help prevent this.

(c) Be prepared to speak to a camera with no audience in front of you. Presenting to a camera is quite different than presenting face-to-face as there are no non-verbal cues from the audience to help guide you. (d) Before you begin, make sure you know how to set the audio levels of your microphone appropriately. Having audio that is too loud or too soft will distract from your message. Audio levels will vary depending on the type of microphone you are using whether it be the built-in microphone on your laptop, external microphone, or earbud-style microphone included with many cell phones. While the built-in microphone on your laptop will get the job done quickly, an external microphone will improve the quality of your audio recording and is recommended for consistent results if you will be doing a large amount of recording.

12. Eliminate any remaining distractions to the students

When giving a video presentation, you want to eliminate all possible distractions for the students. Guidelines 1-3 above will help eliminate content that may distract your students and thus undermine their attainment of your objectives. If you are going to appear on camera, it is also important to consider subtle visual distractions that you might not think about in a live lecture setting.

(a) Avoid clothing that is highly reflective, has tight patterns (e.g., stripes, plaids, checks), or has high contrast patterns as these patterns often result in a shifting pixelation that can be distracting to the audience.

(b) Wear neutral, solid colors and stay aware of the placement of the microphones, if appropriate, as jewelry and fabric folds can affect the audio quality.

(c) Consider your background and/or environment when recording. Make sure your location is aesthetically pleasing. If you are using the camera on your laptop, keep the background as simple as possible. Excessive plants, photos, or other attention-grabbing elements in your environment could be a distraction if you have not properly set up the scene. Setting up your scene includes such considerations as background separation (not sitting too close to a wall), using an external camera with adjustable settings to create depth of field to defocus items further away from the main area, and using lamps or other light sources, to create pools of light to help separate the foreground (you) from the background. These considerations can improve the look of your final product.

Camera placement, regardless of your equipment, should be just below eye level. If using a built-in laptop camera to record your lecture, consider elevating your laptop with books or a stand of some sort to give you a more professional recording angle. When recording with an external camera (cell phone or dedicated DSLR or video camera) be sure to use a tripod to reduce motion. 


\section{Conclusion}

Creating effective pre-recorded slide-based video lectures requires careful consideration of best practices for both presentation development and video creation. These guidelines will help faculty look critically at each part of the processesenabling them to create high-quality recordings that will better engage and instruct students.

Availability of Data and Material Not applicable

Code Availability Not applicable

Authors' Contributions All authors contributed to the conception and design of this document in the order provided.

\section{Compliance with Ethical Standards}

Conflict of Interest The authors declare that they have no conflicts of interest.

Disclaimer The opinions, conclusions, and recommendations expressed or implied do not necessarily reflect the views of the Department of Defense or any other department or agency of the federal government.

\section{References}

1. Allen IE, Seaman J. Online report card: tracking online education in the United States. Oakland (CA): Babson Survey Research Group; 2016. Retrieved from: https://onlinelearningconsortium.org/ 2015Survey

2. Anderson LW, Krathwohl DR, et al., editors. A taxonomy for learning, teaching, and assessing: a revision of Bloom's taxonomy of educational objectives. Boston: Allyn \& Bacon; 2013. (Pearson Education Group)

3. Andre E, Rist T, Muller J. Integrating reactive and scripted behaviors in a life-like presentation agent. Proceedings of AGENTS'98; 1998. p. 261-268.

4. Berg R, Brand A, Grant J, Kirk J, Zimmerman T. Leveraging recorded mini-lectures to increase student learning. Course Des. 2014; 14(2):5-8.

5. Brame, C.J. (2015). Effective educational videos. Retrieved from http://cft.vanderbilt.edu/guides-sub-pages/effective-educationalvideos/.

6. Clark RC, Mayer ER. E-learning and the science of instruction: proven guidelines for consumers and designers of multimedia learning. San Francisco: Pfeiffer; 2008.

7. Dey EL, Burn HE, Gerdes D. Bringing the classroom to the web: effects of using new technologies to capture and deliver lectures.
Res High Educ. 2009;50:377-93. https://doi.org/10.1007/s11162009-9124-0.

8. Dong C, Goh PS. Twelve tips for the effective use of videos in medical education. Med Teach. 2015;37(2):140-5.

9. Gagne, R. M., \& Briggs, L. J. (1974). Principles of instructional design. Holt, Rinehart \& Winston.

10. Green, M. (2018). Are you telling stories in the classroom? Berkeley Teaching Blog. Retrieved from https://teaching. berkeley.edu/news/are-you-telling-stories-classroom.

11. Hughes GD. Using videos to bring lecture to the online classroom. Coll Q. 2009;12(1).

12. Inman J, Myers S. Now streaming: strategies that improve video lectures IDEA Paper \#68. 2018. Retrieved from https://files.eric.ed. gov/fulltext/ED588350.pdf.

13. Jamet $\mathrm{E}$, Le Bohec $\mathrm{O}$. The effect of redundant text in multimedia instruction. Contemp Educ Psychol. 2007;32(4):588-98.

14. Karia A. TED talks storytelling: 23 storytelling techniques from the best TED Talks. Retrieved from Kindle eBook; 2013.

15. Karia A. How to design TED worthy presentation slides. Retrieved from Kindle eBook; 2014.

16. Keller JM. Motivational design for learning and performance: the ARCS model approach. New York: Springer Science \& Business Media; 2009.

17. Khalil MK, Elkhider IA. Applying learning theories and instructional design models for effective instruction. Adv Physiol Educ. 2016;40(2):147-56.

18. Lederman D. How teaching changed in the (forced) shift to remote learning. Inside Higher Educ. 2020. April 22. Retrieved from https://www.insidehighered.com/digital-learning/article/2020/04/ 22/how-professors-changed-their-teaching-springs-shift-remote.

19. Mayer RE, Moreno R. Nine ways to reduce cognitive load in multimedia learning. Educ Psychol. 2003;38(1):43-52.

20. Merrill MD. First principles of instruction: John Wiley \& Sons; 2012.

21. Moore E Adapting PowerPoint lectures for online delivery: best practices. 2013. Retrieved from https://www.facultyfocus.com/ articles/online-education/adapting-powerpoint-lectures-for-onlinedelivery-best-practices/.

22. O'Doherty D, Dromey M, Loughheed J, Hannigan A, Last J, McGrath D. Barriers and solutions to online learning in medical education - an integrative review. BMC Med Educ. 2018;18:130 Retrieved from https://www.ncbi.nlm.nih.gov/pmc/articles/ PMC5992716/.

23. Peterson L. The science behind the art of storytelling. Leading the way: ideas and insights from Harvard Business Publishing Corporate Learning; 2017. Retrieved from https://www. harvardbusiness.org/the-science-behind-the-art-of-storytelling/.

24. Sweller J, van Merriënboer J. Instructional design for medical education. In: Walsh K, editor. Oxford textbook of medical education. Oxford: Oxford University Press; 2013.

25. Tufte ER. The cognitive style of PowerPoint: pitching out corrupts within. Cheshire: Graphics Press LLC; 2006.

Publisher's Note Springer Nature remains neutral with regard to jurisdictional claims in published maps and institutional affiliations. 